\title{
PERANCANGAN E-GUIDEBOOK BANDUNG SELATAN SEBAGAI ALTERNATIF PENANGANAN OVERTOURISM DI KAWASAN BANDUNG UTARA
}

\section{DESIGN OF E-GUIDEBOOK SOUTH BANDUNG AS AN ALTERNATIVE FOR OVERTOURISM HANDLING IN THE NORTH BANDUNG AREA}

\author{
Tiara Fadila Distria*, Irfa Rizkiani Safitri, Nadia Annisa Putri, Eko Susanto \\ Program Studi Usaha Perjalanan Wisata, Politeknik Negeri Bandung \\ Email: tiara.fadila.upw18@polban.ac.id \\ (Diterima 13-12-2020; Disetujui 17-02-2021)
}

\begin{abstract}
ABSTRAK
Buku panduan wisata digunakan sebagai sarana informasi bagi wisatawan bukan hanya untuk mengenalkan tentang potensi di destinasi namun digunakan sebagai pedoman bagi wisatawan saat melakukan perjalanan wisata. Buku panduan wisata digital lebih efektif dibanding buku panduan wisata konvensional, karena lebih mudah diakses melalui gawai. Salah satu penerapan panduan wisata digital dapat diterapkan untuk destinasi wisata Pangalengan Kabupaten Bandung, dengan potensi wisata yang tidak kalah menarik dari kawasan Bandung Utara. Tujuan perancangan buku panduan wisata digital pada proyek ini adalah untuk memberikan informasi sekaligus promosi wisata Pangalengan kepada wisatawan agar dapat menjadi alternatif destinasi selain Bandung Utara yang telah mengalami permasalahan overtourism. Metode perancangan yang digunakan yaitu pengumpulan data, sortasi data, perancangan buku panduan wisata digital, uji pasar dan evaluasi. Dalam buku panduan wisata digital ini terdapat 4 komponen utama yaitu Attractions, Accessibility, Amenity, dan Ancillary. Keempat komponen utama tersebut akan menjadi konsep dasar perancangan buku panduan wisata digital Bandung Selatan. Buku panduan wisata digital Bandung Selatan ini diharapkan bermanfaat bagi wisatawan, pengelola pariwisata di Pangalengan, Dinas Pariwisata Kabupaten Bandung dan para pelaku wisata lainnya.
\end{abstract}

Kata Kunci: Buku Panduan Wisata Digital, Overtourism, Promosi wisata

\begin{abstract}
Travel guidebooks are used as a means of information for tourists not only to introduce the potential in a destination but are used as new ones for tourists when traveling. Digital travel guidebooks are more effective than conventional travel guidebooks because they are easier to access via mobile devices. One of the applications of digital travel guides can be applied to tourist destinations in Pangalengan, Bandung Regency, with tourism potential that is no less attractive than the North Bandung area. The purpose of designing a digital travel guidebook in this project is to provide information as well as promote Pangalengan tourism to tourists so that they can become an alternative destination other than North Bandung which has experienced overtourism problems. The design method used is data, sorting data, designing a digital travel guide book, market testing, and evaluation. In this digital travel guide book, there are 4 main components, namely Attractions, Accessibility, Facilities, and Additions. The four main components will form the basic concept of designing a digital travel guide for South Bandung. The South Bandung digital travel guide book is expected to be useful for tourists, tourism managers in Pangalengan, the Bandung Regency Tourism Office, and other tourism actors.
\end{abstract}

Keyword: E-guidebook, Overtourism, Tourist Promotion

\section{PENDAHULUAN}

Teknologi telah berkembang sangat pesat, terdapat inovasi baru setiap tahun dari penerapan teknologi khususnya pada teknologi informasi. Hampir seluruh sektor di dunia membutuhkan dan menerapkan teknologi informasi untuk mempermudah dalam berkomunikasi. Teknologi dapat merubah pola bisnis pada industri pariwisata, terutama 
Perancangan E-Guidebook Bandung Selatan Sebagai Alternatif Penanganan Overtourism Di Kawasan Bandung Utara Tiara Fadila Distria, Irfa Rizkiani Safitri, Nadia Annisa Putri, Eko Susanto

pada konsep smart tourism (Susanto, et al, 2020) (Rusdi, 2017). Bagi sektor pariwisata, teknologi informasi dapat meningkatkan optimalisasi pada perusahaan (Xiang, 2018). Kelebihan teknologi lainnya yang dapat diterapkan pada industri pariwisata adalah pada mobile computing yaitu merupakan teknologi yang dapat dibawa kemana-mana seperti halnya smartphone (Rusdi, 2019). Dengan adanya pemanfaatan mobile computing ini dapat menjadi peluang bagi industri pariwisata. Kebutuhan yang bersifat konvensional pada aktivitas pariwisata dapat beralih menjadi digital dengan bantuan teknologi, salah satunya diterapkan pada buku panduan wisata, dari buku saku beralih menjadi buku panduan wisata digital atau e-guidebook.

E-guidebook dapat mempermudah dalam mendapatkan informasi terkait suatu destinasi wisata, khususya bagi wisatawan dengan pengetahuan awam akan destinasi tertentu, maka e-guidebook dapat membantu mendapatkan informasi penting dan menarik. Dampak lain yaitu dapat membentuk keinginan wisatawan dalam berwisata (Manzor, et al, 2017). Guidebook juga dianggap dapat berperan aktif dalam komunikasi antara wisatawan dan masyarakat lokal dan membangun gambaran tentang tempat-tempat wisata yang mereka kunjungi (Lever, et al, 2019).

Buku panduan perjalanan idealnya berisikan informasi terkait objek wisata, akomoda, transportasi, amenitas, fasilitas pendukung hingga tentang cara berperilaku di suatu daerah. Mempertimbangkan hal tersebut, penting untuk dilakukan perancangan $e$ guidebook bagi destinasi wisata berkembang di Indonesia, khususnya Bandung Raya.

Kawasan Bandung Raya sebagai episentrum pariwisata Jawa Barat menjadi destinasi yang paling banyak dikunjungi wisatawan karena potensi wisata yang sangat besar, terutama pada segmen wisata alam. Jumlah kunjungan wisatawan ke objek wisata di wilayah Bandung sebanyak 10,372,669 kunjungan meliputi Kota Bandung, Kabupaten Bandung, dan Kabupaten Bandung Barat (BPS Jawa Barat, 2019). Jumlah kunjungan yang sangat besar tersebut menyebabkan peningkatan kepadatan wisatawan khususnya di Kota Bandung dan Kawasan Bandung Utara. Dalam kepariwisataan, fenomena ini mengarah pada kondisi yang dikenal dengan istilah overtourism (Dodds \& Butler, 2019).

Bandung Selatan memiliki karakteristik produk wisata yang hampir sama dengan kawasan Bandung Utara, namun banyak wisatawan yang belum mengetahui potensi wisata yang dimiliki kawasan ini. Landcsape pegunungan dengan fitur alam berupa perkebunan teh, danau, hutan, cagar alam dan kawah gunung berapi mampu ditawarkan Kawasan Wisata Bandung Selatan. Beberapa destinasi unggulan di wilayah ini yaitu Kawah Putih, 
Situ Patenggang, Perkebunan Teh Maribaya, Situ Cileunca, Sunrise Point Cukul, Situ Cisanti hingga Wayang Windu.

Kesenjangan perkembangan Kawasan Wisata Bandung Selatan dengan Kawasan Wisata Bandung Utara juga dapat terlihat dari popularitas kawasan di kalangan wisatawan. Wisata di kawasan Bandung Utara lebih banyak dikunjungi wisatawan dan menjadi pilihan utama untuk dikunjungi pada akhir pekan. Namun, berbanding terbalik dengan Pangalengan yang belum dijadikan pilihan utama wisatawan untuk menghabiskan akhir pekannya. Bahkan sebagian besar dari mereka belum mengetahui sama sekali terkait wisata Bandung Selatan terutama kawasan Pangalengan.

Dengan potensi-potensi wisata yang melimpah di kawasan Pangalengan tidak menutup kemungkinan ke depannya kawasan ini bisa menjadi pilihan utama wisatawan saat akhir pekan. Namun, karena kurangnya informasi yang diterima wisatawan terkait wisata di Pangalengan menjadikan kawasan ini belum dikenal banyak orang. Dari permasalahan tersebut, solusi yang bisa diberikan yaitu dengan perancangan e-guidebook kawasan Pangalengan yang bisa digunakan sebagai sarana informasi dan promosi kepada wisatawan untuk mengenal potensi-potensi wisata di Pangalengan.

Perancangan ini diharapkan dapat bermanfaat bagi pelaku pariwisata seperti wisatawan, Dinas Priwisata Kabupaten Bandung dan pengelola destinasi wisata yang ada di Bandung Selatan.

\section{BAHAN DAN METODE}

Perancangan proyek ini dilakukan dengan beberapa tahap, yaitu:

1 Pengumpulan data melalui studi literatur dengan mengumpulkan data dari proyek sejenis untuk dijadikan referensi.

2 Sortasi data: yaitu memilah dan menyederhanakan data untuk kemudian diolah untuk dijadikan konsep dasar perancangan e-guidebook.

3 Perancangan buku panduan: setelah mendapatkan data-data yang diperlukan maka selanjutnya dilakukan penentuan tema, isi dan layout dari e-guidebook.

4 Uji pasar: setelah produk selesesai maka akan dilakukan uji pasar untuk mengetahui kekurangan yang terdapat pada e-guidebook. selain itu, juga untuk melihat minat pasar terhadap e-guidebook yang telah dibuat.

5 Finalisasi, dalam tahap ini produk yang telah diuji pasar akan diperbaiki jika ada kekurangan dan jika dirasa sudah baik maka bisa dipublikasikan. 


\section{HASIL DAN PEMBAHASAN}

Dari hasil studi konsep e-guidebook dan studi literatur proyek sejenis, dirancang sebuah e-guidebook Bandung Selatan yang menerapkan unsur 4A sebagai indikator utamanya yaitu attraction, accessibility, amenity dan ancillary.
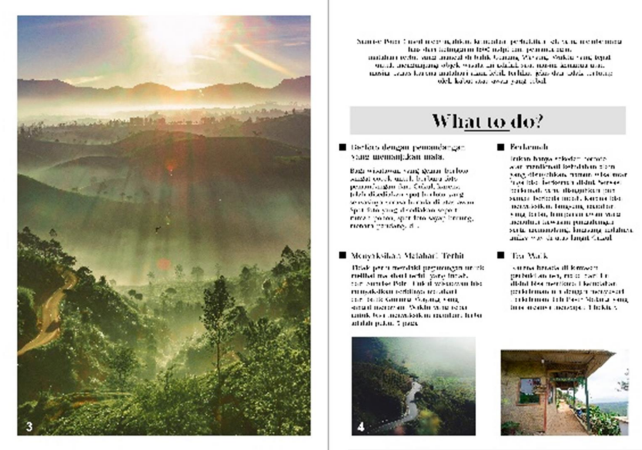

Gambar 1. Tampilan Rekomendasi Aktivitas

\section{Attraction}

Dalam sebuah destinasi wisata hal yang paling utama adalah adanya atraksi wisata yang bisa dinikmati oleh wisatawan. Indikator atraksi di dalam e-guidebook ini memuat penjelasan singkat terkait objek wisata, lokasi dan piihan kegiatan yang bisa dilakukan oleh wisatawan. Objek wisata yang dipilih untuk dimasukkan ke dalam E-guidebook Bandung Selatan ini adalah Sunrise Point Cukul, Situ Cileunca, Hutan Pinus Rahong, dan Wayang Windu Panenjoan. Keempat objek wisata tersebut menyuguhkan kegiatan yang menarik disertai dengan pemandangan alam serta mampu memberikan kenyamanan bagi wisatawan.

\section{Accessibility}

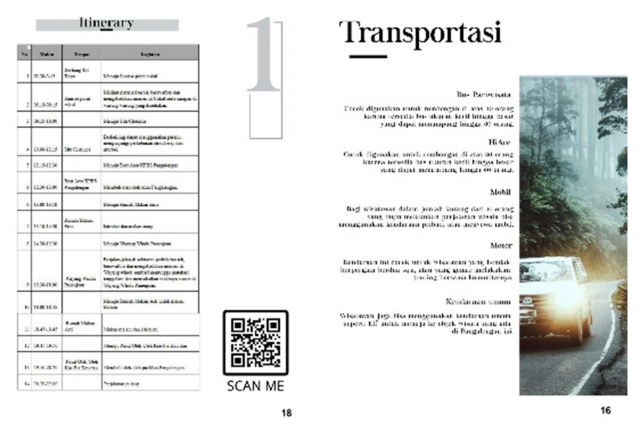

Gambar 2. Tampilan Rekomendasi Itinerary

Untuk dapat mencapai destinasi, diperlukan akses baik dari sisi pemilihan rute perjalanan atau pilihan moda transportasi. E-guidebook Bandung Selatan ini memberikan rekomendasi jenis-jenis kendaraan yang dapat digunakan untuk menuju destinasi wisata di Pangalengan. 
Tersedia 2 rekomendasi rute beserta itinerary selama satu hari penuh yang dapat dijadikan acuan wisatawan. Rute pertama diawali dari Gerbang Tol Kopo - Sunrise Point Cukul - Situ Cileunca - Rest Area KPBS - Rumah Makan Erna - Wayang Windu Panenjoan - Rumah Makan Asti - Kue Pia Kawitan. Untuk rute kedua diawali dari Gerbang Tol Soroja - Sunrise Point Cukul - Hutan Pinus Rahong - Rumah Makan Erna TK Caramel - Wayang Windu Panenjoan - Kue Pia Kawitan - Rumah Makan Tangek.

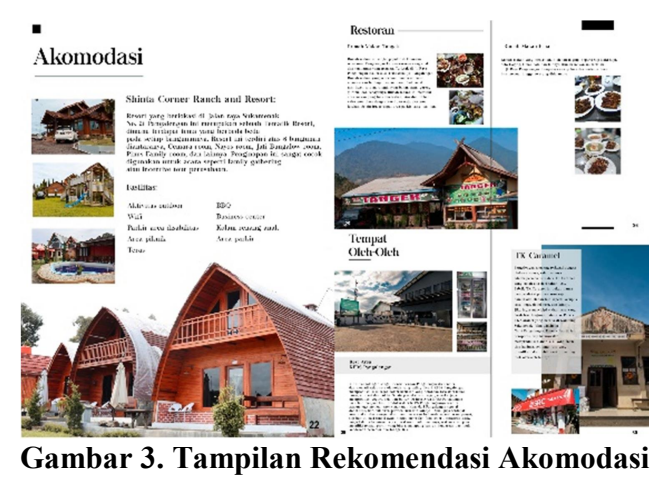

\section{Amenity}

Amenitas menjadi faktor penunjang destinasi wisata setelah faktor atraksi, sehingga penyediaan amenitas menjadi hal yang harus dilakukan oleh para pelaku wisata. Fasilitas dalam perancangan ini berupa akomodasi, restoran dan tempat oleh-oleh. Akomodasi yang dipilih adalah The Bloem Lakeview Villa, Hotel Puri Pangalengan, dan Shinta Corner Ranch. Setiap akomodasi memiliki keunikan tersendiri dan lokasi yang strategis serta dilengkapi dengan fasilitas yang lengkap. Pilihan restoran yaitu Rumah Makan Erna dengan menu yang fokus pada olahan daging, Rumah Makan Asti dengan menu andalan berupa sop buntut, serta Rumah Makan Tangek yang sudah cukup terkenal di kalangan wisatawan Pangalengan.

Pangalengan terkenal dengan olahan susu KPBS serta berbagai macam olahan susu lainnya. Lokasi oleh-oleh yang dipilih adalah Rest Area KPBS Pangalengan, TK Caramel, dan Kue Pia Kawitan.

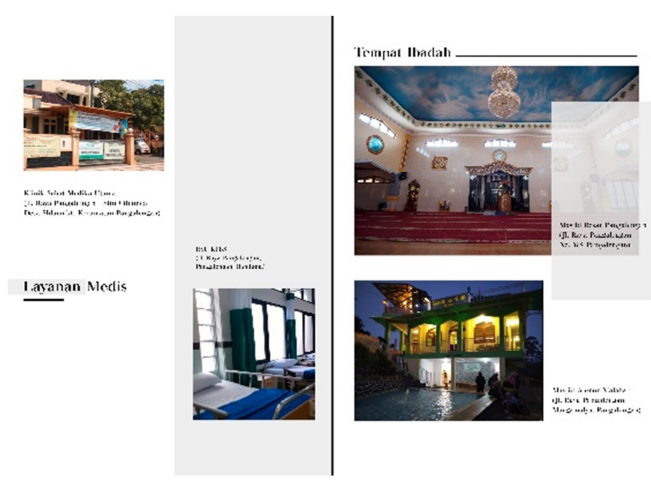

Gambar 4. Tampilan Rekomendasi Layanan Pendukung 


\section{Ancillary}

Destinasi perlu didukung oleh fasilitas seperti ATM, minimarket, pom bensin, toilet umum, tempat ibadah, layanan medis dan lainnya. Fasilitas pendukung ini sangat dibutuhkan dan menjadi salah satu indikator utama yang harus ada dalam suatu destinasi. Rekomendasi fasilitas pendukung terdapat pada e-guidebook Bandung Selatan ini adalah tempat ibadah dan fasilitas medis.

Hasil perancangan e-guidebook ini akan didistribusikan kepada masyarakat luas melalui instagram@wisatapangalengan yang pada dasarnya memang memuat kontenkonten pariwisata di Pangalengan serta telah memiliki follower yang cukup sehingga dapat dijadikan sebagai media distribusi e-guidebook Bandung Selatan. Produk perancangan ini juga dapat diakes pada link: https://bit.ly/GuidebookBandungSelatan.

\section{KESIMPULAN}

Bandung menjadi salah satu destinasi wisata favorit bagi wisatawan terutama wilayah Bandung Utara dan Bandung Selatan. Wilayah ini dapat menjadi pilihan terbaik bagi wisatawan yang ingin menikmati wisata alam, karena memiliki potensi wisata alam yang banyak dan indah, namun popularitasnya masih dibilang sangat jauh dari Bandung Utara. Disamping popularitas wisata Bandung Utara yang besar, terdapat dampak negatif dari banyaknya wisatawan yang mengunjungi kawasan Bandung Utara yaitu overtourism atau jumlah wisatawan yang berlebih dalam suatu destinasi, sehingga menimbulkan kualitas wisata yang menurun.

Guidebook merupakan salah satu sarana informasi wisata yang dapat digunakan sebagai pedoman wisatawan. Guidebook dapat menjadi salah satu sarana promosi untuk memperkenalkan potensi wisata pada suatu destinasi.

Perancangan E-guidebook Bandung Selatan dapat menjadi sarana informasi bagi wisatawan yang ingin mengetahui potensi-potensi wisata yang dimiliki oleh Pangalengan lebih baik lagi. Selain itu juga, buku ini bisa berperan sebagai sarana promosi wisata agar meningkatkan popularitas Bandung Selatan. Buku ini juga diharapkan dapat meningkatkan kunjungan di kawasan Bandung Selatan sehingga bisa menjadi alternatif penanganan overtourism di kawasan Bandung Utara.

\section{UCAPAN TERIMAKASIH}

Penyusun mengucapkan terimakasih kepada Politeknik Negeri Bandung yang telah memberikan dukungan pendanaan perancangan ini. Terimakasih kepada Pemerintah 
Kabupaten Bandung sebagai mitra perancangan dan Wisata Pangalengan yang telah menjadi media partner dalam mempublikasikan produk e-guidebook Bandung Selatan.

\section{DAFTAR PUSTAKA}

Badan Pusat Statistika Jabar. (2019, November 27). Retrieved 10 27, 2020, from https://www.jabar.bps.go.id

Dodds, R., \& Butler, R. (2019). The Phenomena of Overtourism: A review. International Journal of Tourism Cities, 5(4): 519-528.

Lever, M., Shen, Y., \& Joppe, M. (2019). Travel Guidebooks: Readership Typologie Using Eye-tracking Technology. Journal of Destination Marketing \& Management, 14(2019) 100368: 1-13.

Mazor-Trigerman, M., Mansfeld, Y., \& Elyda, O. (2017). Travel Guidebook and The Construction Tourist Identity. Journal of Tourism and Cultural Change, 15(1): 8098.

Rusdi, J. F. (2017). Kolaborasi Pariwisata Bandung Raya. Indonensia Tourism Journalist Association,

Rusdi, J. F. (2019). Peran Teknologi Informasi Pada Pariwisata Indoneisa. Jurnal Accounting Information System (AIMS), 2(2): 78-118.

Susanto, E., Novianti, S., Rafdinal, W., Prawira, M. F., \& Septyandi, C. B. (2020). Visiting Tourism Destination: Is It Influenced by Smart Tourism Technology? Journal of Indonesian Tourism and Development Studies. 8(3): 145-155.

Xiang, Z. (2018). From digitization to the age of acceleration: On information technology and tourism. Tourism Management Perspective, 25, 147-150. 